\title{
O Vazio de Sentido: Suporte da Religiosidade para Pacientes com Câncer Avançado
}

\author{
Cristine Gabrielle da Costa dos Reis \\ Universidade Federal de Santa Maria, RS, Brasil. \\ Camila Peixoto Farias \\ Universidade Federal de Santa Maria, RS, Brasil. \\ Alberto Manuel Quintana \\ Universidade Federal de Santa Maria, RS, Brasil.
}

\begin{abstract}
Resumo: Pacientes com câncer avançado, muitas vezes, deparam-se com um vazio de sentido, tanto por conta de movimentos externos, como o afastamento e falta de olhar da equipe, de amigos e familiares, quanto por dimensões subjetivas e singulares relacionadas à vivência da doença. Com isso, objetivou-se compreender quais os sentidos que os pacientes constroem para a vivência do adoecimento grave. Foi realizada uma pesquisa descritiva e exploratória, de cunho qualitativo, com 12 pacientes com câncer avançado, internados no serviço de Hematologia-Oncologia de um hospital-escola do interior do Rio Grande do Sul, com base em entrevistas semiestruturadas e análise de conteúdo. Verificou-se que os entrevistados buscaram construir um sentido para sua vivência, predominantemente por meio da religiosidade, que lhes ofereceu possibilidades de compreensão, suporte, conforto, sentimento de controle, entre outras construções de significação para a doença. Foi possível perceber que, por vezes, a religiosidade não se mostrou suporte suficiente para o trabalho de construção de significados para o adoecimento. Assim, pensa-se que a religiosidade é capaz de lhes trazer certas explicações e suportes diante do esvaziamento dos sentidos provocado pela doença, contudo, faz-se necessário que outras estratégias sejam construídas para auxiliar o paciente a lidar com as angústias frente à doença e à possibilidade de morte.
\end{abstract}

Palavras-chave: Morte, Neoplasias, Religiosidade, Significado.

\section{Emptiness of sense: religiosity support for patients with advanced cancer}

\begin{abstract}
Patients with advanced cancer face, many times, emptiness of sense, due both to external movements, such as the distance and lack of attention of the health professionals, friends and family, and to subjective and singular dimensions related to the illness experience. Thus, this study aimed to comprehend what are the senses attributed by the patients to the experience of serious illness. Therefore, it was conducted a qualitative, descriptive and exploratory research, with twelve patients with advanced cancer, hospitalized in the division of Hematology-Oncology of an university hospital, in the state of Rio Grande do Sul. Data were collected through semistructured interviews and the analysis was based in the content analysis. It was found out that the participants tried to build a sense for their experience, mainly through religiosity, that would offer them possibilities of comprehension, support, comfort, sense of control, among other significations for the illness. However, it was shown that, sometimes, religiosity was not a sufficient support in the task of building meanings for the illness. Thus, it is assumed that religiosity is capable of bringing them some answers and support when facing the emptiness of senses caused by the illness; nevertheless, the development of other strategies is necessary in order to assist the patient while dealing with the distress in face of the illness and of the death possibility.
\end{abstract}

Keywords: Death and Dying, Neoplasms, Religiosity, Meaning. 


\title{
El vacío de sentido: soporte de la religiosidad para pacientes con cáncer avanzado
}

\begin{abstract}
Resumen: Los pacientes con cáncer avanzado, muchas veces, se deparan con un vacío de sentido, tanto por movimientos externos, como el alejamiento y la falta de atención del equipo, amigos y familiares, como por dimensiones subjetivas y singulares relacionadas a la vivencia de la enfermedad. Así, se buscó comprender los sentidos que los pacientes construyen para la vivencia de una enfermedad grave. Para tal fin, se utilizó una investigación descriptiva y exploratoria, de naturaleza cualitativa, realizada con doce pacientes con cáncer avanzado, internados en el servicio de Hematología-Oncología de un hospital-escuela del interior de Rio Grande do Sul. La recolección de datos se realizó con entrevistas semiestructuradas y el análisis a través del análisis de contenido. Se entendió que los entrevistados buscaron construir un sentido para la vivencia, predominantemente por medio de la religiosidad, lo que les ofreció posibilidades de comprensión, sustento, consuelo, sentimiento de control, entre otros. Además, fue posible percibir que, a veces, la religiosidad no se mostró suficiente como sustento para el trabajo de construcción de significados para la enfermedad. Así, se piensa que la religiosidad es capaz de traer ciertas explicaciones y soporte frente a la pérdida de los sentidos provocados por la enfermedad; sin embargo, es necesario que otras estrategias sean construidas para auxiliar al paciente a tratar con las angustias frente a la enfermedad y a la posibilidad de muerte.
\end{abstract}

Palabras clave: Muerte, Neoplasmas, Religiosidad, Significado.

\section{Introdução}

Há uma concepção, no senso comum, que associa o câncer à morte, o que faz com que ele seja visto como uma doença incurável. Tal associação gera um sentimento de impotência frente à enfermidade, como se tudo que o doente fizesse fosse em vão. Com isso, produzem-se diversas repercussões na vida da pessoa com câncer que estão intimamente ligadas ao modo como ela construiu o seu processo de viver, sua subjetividade (Rzeznik, \& Dall'Agnol, 2000).

Diante da negação da morte nos dias atuais e da dificuldade dos profissionais da saúde de lidarem com pacientes cujas doenças estão associadas à morte, como, por exemplo, o câncer avançado, aqui definido como aquele que recursos terapêuticos curativos são menos eficazes para a cura, embora possam ajudar com que o tumor cresça de maneira mais lenta (American Cancer Society, 2014), há um movimento de afastamento desses profissionais, deixando, muitas vezes, de escutar os pacientes e de assisti-los emocionalmente. Essa falta de assistência emocional acaba por dificultar a aceitação e as possibilidades de construção de um sentido para a vivência da doença, tornando o processo ainda mais difícil.
Acredita-se que o pouco espaço dado à expressão de sentimentos e angústias frente à morte e a escassez de recursos para lidar com a problemática do fim da vida representam a base do mal-estar entre paciente terminal e equipe (Quintana, Kegler, Santos, \& Lima, 2006). Esse mal-estar que se instala dificulta tanto a relação entre ambos (paciente e equipe) quanto a relação do paciente com sua própria doença, uma vez que se torna ainda mais difícil construir um sentido para o adoecimento em um meio que não oferece espaços de diálogo e amparo.

É imprescindível destacar a importância da esfera subjetiva no enfrentamento da doença. Mori (2015) ressalta que é preciso reconhecer a atuação das pessoas nos processos de saúde e doença e reitera que não se trata de objetivar a visão do câncer como algo determinante da condição do indivíduo, mas, sim, visualizar os diferentes sentidos que são produzidos nesse contexto em termos subjetivos, uma vez que tais sentidos são produzidos social e individualmente. Diante disso, entende-se que há diversas representações sociais relacionadas ao câncer, porém, cada paciente pode subjetivar e atribuir sentido a tal experiência de acordo com sua singularidade, ou seja, suas representações, crenças e emoções (Mori, 2015). 
Tendo isso em vista, sugere-se a importância tanto dos aspectos externos, no que diz respeito ao ambiente, equipe e relações, quanto da própria estrutura subjetiva do ser. Nesse sentido, o adoecimento por câncer é um processo tanto singular quanto relacional e social. Mesmo que os indivíduos possam significá-lo de maneiras diversas, Menezes, Schulz e Peres (2012) ressaltam, com base em seu estudo, que o diagnóstico de câncer causou, em uma parcela expressiva dos participantes, um impacto psicológico importante. Tal impacto pode ser pensado como um abalo nas possibilidades de elaboração psíquica do paciente. O processo de elaboração psíquica é conceituado como um trabalho, realizado pelo aparelho psíquico do indivíduo, com o objetivo de dominar as excitações que se apresentam a ele e que correm o risco de acumularem-se, tornando-se patogênicas (Laplanche, \& Pontalis, 2001). A realização do trabalho de elaboração psíquica indica a possibilidade de construção de sentidos para as excitações que chegam ao psiquismo. Quando o indivíduo não consegue realizar tal trabalho, nem construir sentidos ou dominar excitações muito intensas que chegam a seu psiquismo, pode-se pensar que isso produz um vazio de sentido. Tendo isso em vista, a situação da doença terminal pode produzir excitações que ele não tem capacidade de dominar e nem de construir um sentido para elas. Essa situação gera uma demanda por uma significação e acaba desencadeando o levantamento de questões como: o que está acontecendo comigo? e, posteriormente: por que tudo isto está acontecendo comigo? (Quintana, 1999), uma vez que, segundo Redon (2008), os "porquês" (por que não estar saudável?, por que ter sido ele o escolhido?) não podem ser satisfatoriamente respondidos com explicações puramente biológicas.

Nesse sentido, há uma intenção de conhecer a causa da doença, mas, principalmente, há uma busca de sentido que possa dar conta do que se refere ao mal biológico (Quintana, 1999). Frente à falta de explicação, aos diversos questionamentos e à busca de sentido, é comum que os pacientes recorram a explicações de ordem religiosa. Uma pesquisa de Caetano, Gradim e Santos (2009), realizada com 15 mulheres portadoras do câncer de mama, revelou que a principal alternativa buscada por elas para enfrentarem o tratamento foi a fé em Deus. Apesar de o estudo tratar de um câncer específico, sugere-se que é possível fazer uma transposição para situações limítrofes, como outros tipos de câncer.
Entende-se que o presente estudo possa contribuir para o conhecimento mais aprofundado sobre como se dá a busca por significados e quais sentidos os pacientes com câncer avançado constroem para a doença que estão vivenciando. Além disso, destaca-se a sua importância no sentido de permitir que profissionais possam refletir sobre suas práticas com esses indivíduos. Assim, o estudo poderá fornecer ferramentas importantes aos profissionais para auxiliar os pacientes no processo de construção de significação da situação de adoecimento pela qual estão passando.

\section{Câncer: um mistério?}

A concepção sobre a morte sofreu alterações ao longo dos tempos, e, consequentemente, a forma como as pessoas a encaram mudou. A morte não só é um processo biológico e natural como também é constituída por aspectos psicológicos e sociais. Diante disso, é entendida como um processo impregnado de valores e significados que dependem do contexto social e histórico em que se manifesta (Combinato, \& Queiroz, 2006).

Tendo isso em vista, na Idade Média europeia, por exemplo, a morte fazia parte do ambiente doméstico das pessoas, sendo entendida de forma natural (Combinato, \& Queiroz, 2006). Na contemporaneidade, por sua vez, aponta-se a exclusão da problemática da morte do âmbito social, estando ela reclusa apenas a locais determinados, como os hospitais e instituições de saúde, nos quais passa a estar permeada por uma conotação de assepsia, isolamento afetivo e negação (Campos, 2013).

Nesse sentido, tem-se que, por volta do século passado, as doenças responsáveis pela ameaça à vida eram predominantemente infecciosas, como a cólera, a sífilis e a tuberculose. A tuberculose era temida de maneira aguda e desempenhava um papel de doença intratável e cruel, sendo apavorante não só pelo seu caráter contagioso, mas por ser uma desgraça aparentemente arbitrária. Com isso, algumas doenças, ao longo do tempo, passaram a desempenhar o papel de um mal não compreendido, cercadas por estereótipos negativos, representando um lado obscuro da vida e uma ameaça a esta (Sontag, 1984).

Com o avanço técnico-científico e o desenvolvimento de antibióticos no mundo ocidental, infecções mais comuns passaram a ser combatidas, reduzindo, assim, o índice de mortalidade (Doyle, Hanks, \& MacDonald, 2006). Uma vez descoberta a cura e a prevenção para um dos males do século, a tuberculose dei- 
xou de ser misteriosa e de carga mortal. Dessa maneira, houve uma passagem das mortes por doenças infecciosas para as mortes por doenças crônicas degenerativas.

As doenças crônicas graves, como o câncer, convocam o assunto morte, tornando-o presente desde o diagnóstico, estendendo-se, muitas vezes, ao pós-tratamento. É notável que em grande parte da população prepondera ideias sobre o câncer como sinônimo de morte, que não pode ser controlado e que o tratamento sempre é drástico e negativo (Dóro, Pasquini, Medeiros, Bitencourt \& Moura, 2004). Sendo o câncer, frequentemente, associado à ideia de morte, o diagnóstico tem uma expressão significativa de um suposto atestado de óbito (Dóro et al., 2004). Numa era em que a máxima da medicina é de que todas as doenças podem ser curadas, cria-se um mistério em torno do câncer, que, popularmente, não é considerado apenas uma doença, mas uma maldição invencível e destruidora (Sontag, 1984). Esses aspectos, articulados a forma singular de cada paciente lidar com as excitações provocadas pelo adoecimento, podem tornar o processo de construção de sentidos para a doença difícil e desafiador.

\section{Em busca de um sentido}

Tal imagem criada em torno do câncer, a qual está associada à possiblidade de morte, somada à falta de explicações por parte da equipe e as singulares excitações que tal situação provoca, resulta no confronto com a ausência de significação para a vivência pela qual os pacientes estão passando. Ao deparar-se com a doença e a morte, o indivíduo é posto frente a frente à sua fragilidade e à falta de sentido, questionando-se a respeito de suas construções simbólicas. Assim, os indivíduos se veem diante de um vazio de significados, que os impulsiona a buscar reconstruir o sentido de sua existência. Esse vazio que o confronto com a possibilidade de morte traz pode ser resignificado por meio de ritos, que possibilitam novas construções simbólicas (Quintana, 1999).

O cotidiano do paciente se mostra como uma rotina de exames e tratamento. Tal cotidiano traz uma série de consequências que aproximam o paciente da possibilidade de morte, como a debilidade física do corpo, o olhar de proteção do outro, denúncia e sufoco. A debilidade física do corpo acaba impondo alguns limites às pessoas, o que pode causar mudanças nas relações com os outros e consigo mesmo, uma vez que tais limitações causam falta de apetite, fraqueza corporal constante e dependência de outros para realizações de atividades consideradas corriqueiras. Diante disso, tais repercussões podem afetar a situação de esperança de vida e de cura, pois as marcas físicas evidentes que $o$ avanço do câncer causa fazem com que os pacientes se confrontem, cada vez mais, com a possibilidade concreta da sua finitude (Trincaus, \& Corrêa, 2007). Dessa forma, à medida que tais limitações afetam as relações com os outros e consigo mesmo, bem como abalam a esperança de vida, a falta de sentido se torna ainda mais presente, fazendo com que o indivíduo se depare com sua fragilidade.

A doença, pela intensidade das excitações que provoca, abre uma fissura no universo simbólico que clama por significação, sob ameaça de que todo o restante do universo simbólico daquele indivíduo possa também perder o sentido. Dessa maneira, com o aparecimento da doença, surge a falta de sentido, de modo que o sagrado aparece como recurso frente a essas situações de falta de significação. Entende-se, dessa forma, que a possibilidade de simbolizar e integrar essas vivências em um contexto significativo permite que o indivíduo possa transformar o perigoso e ameaçador em algo palpável, que se pode recorrer, e, assim, passível de ser modificado e elaborado (Quintana, 1999).

Nesse contexto, a religiosidade ocupa um espaço importante, como mostra o estudo de Geronasso e Coelho (2012) sobre a influência da religiosidade/espiritualidade na qualidade de vida das pessoas com câncer. Os participantes do estudo atribuíram à fé diversos sentidos como suporte e força para superar a dor e o sofrimento, bem como o auxílio para o controle emocional. Ainda, a pesquisa mostrou que a fé possibilita uma ressignificação da doença. Nessa direção, Guerrero, Zago, Sawada e Pinto (2011) apontam, com base em sua pesquisa com pacientes oncológicos, que a submissão a Deus sugere o domínio da entidade divina sobre a vida das pessoas. Diante disso, o acaso é explicado, os eventos imprevisíveis, como a doença, tornam-se previstos e a segurança dada pelo divino ocupa o lugar da fatalidade. Dessa maneira, os processos mágico-religiosos passam a ser usados de forma a tentar dar um contorno para uma situação marcada pelo vazio de sentido e minimizar o sentimento de impotência do ser humano (Quintana, 1999).

Tendo em vista que o processo de adoecimento por câncer coloca o indivíduo em uma situação de impotência e de fragilidade, exigindo que novos recur- 
sos psíquicos e sociais sejam construídos para lidar com a doença, isso nos motivou a ouvir tais pacientes visando conhecer o modo como eles significam o processo do seu adoecimento. Nesse sentido, o estudo objetiva compreender como os pacientes, frente a um conjunto de mudanças inesperadas, constroem um sentido para a vivência da doença. Isso por que se compreende que há uma série de mudanças conflitivas em relação à vida do indivíduo a partir do surgimento e avanço da doença, que exigem a construção de novos sentidos para o viver.

\section{Método}

\section{Desenho do estudo}

O estudo trata de uma pesquisa descritiva e exploratória, de cunho qualitativo. Optou-se pelo método qualitativo por melhor abordar o assunto, uma vez que busca explorar as questões existenciais presentes nos indivíduos, como angústia e ansiedade, e capturar os sentidos e significações dos fenômenos, por meio da escuta e observação dos participantes da pesquisa, da criatividade e interpretação (Turato, 2003). No que se refere à pesquisa exploratória, esta foi escolhida por ter como objetivo buscar uma maior familiaridade com o problema, visando torná-lo mais explicativo. Seu objetivo principal é o aprimoramento de ideias ou descoberta de percepções, sendo, portanto, bastante flexível. Já a pesquisa descritiva foi selecionada por ter como aspecto central a descrição das características de determinado fenômeno ou população (Gil, 2002).

\section{Cenário do estudo}

No que se refere ao cenário de estudo para coleta de dados, Turato (2003) destaca que o lugar mais adequado para tal é o ambiente natural do participante do estudo, onde se encontrarão informações realmente válidas, uma vez que são conservadas as características e relações do participante. A relação entrevistador-entrevistado permite uma apreensão ampla dos fenômenos do universo psíquico deste. Assim, em uma pesquisa que possui o homem como objeto de estudo, o trabalho de campo traz uma maior riqueza, agregando valores de autoridade e validade (Turato, 2003). O serviço de Hematologia-Oncologia do hospital onde foi realizada a pesquisa é composto por seis consultórios, 18 leitos para quimioterapia ambulatorial, 18 leitos pediátricos, cinco leitos no Centro de Transplante de Medula Óssea (CTMO) e 20 leitos para pacientes adultos na Clínica Médica II, local este onde foram realizadas as entrevistas.

\section{Participantes da pesquisa}

Da presente pesquisa, fizeram parte 12 participantes diagnosticados pela equipe de saúde da Hematologia-Oncologia do hospital com câncer avançado e que estavam em tratamento no hospital. Para tal, houve o prévio consentimento dos pacientes. Da totalidade dos entrevistados, 11 eram do sexo masculino e apenas um do sexo feminino. Com o intuito de preservar a identidade dos mesmos, seus nomes serão trocados pela letra "E" seguida de um número que identifica participante, na sequência, a letra "M" ou " $F$ " identificando o sexo, e, finalmente, um número referente às suas idades.

A fim de delimitar o número de entrevistas, utilizou-se o critério de saturação. Este critério estabelece que há um número limitado de versões da realidade. Isso se dá porque, mesmo que as experiências possam parecer únicas ao indivíduo, elas resultam também de processos sociais. Nesse sentido, representações de um tema em comum, ou de pessoas em um meio social específico, são, em parte, compartilhadas. Dessa maneira, gradativamente, os temas em comum começam a surgir, sendo possível elaborar uma interpretação de tais (Bauer, \& Gaskell, 2008).

\section{Coleta de dados}

As coletas de dados foram feitas por meio de entrevistas semiestruturadas, de questões abertas, pois, segundo Turato (2003), a direção pode, assim, ser dada por ambos integrantes da relação, além de oferecer espaço para o entrevistado colocar livremente o conteúdo da sua resposta, em vez de se restringir às alternativas dadas pelo pesquisador. A entrevista contou com um roteiro que se constituía por tópicos que contemplavam a abrangência das informações esperadas. Ele serviu como um guia e foi construído de modo a permitir a flexibilidade nas conversas e absorção de novos temas trazidos pelo entrevistado, a fim de promover uma abertura às interpretações do indivíduo, assim como de suas visões sobre as relações sociais (Minayo, 2010). Em uma média, as entrevistas 
duraram cerca de 30 minutos, e foram realizadas no leito em que os pacientes estavam internados, sendo que a sua maioria encontrava-se em isolamento. A grande parte dos pacientes estava acompanhada por um familiar, pelo menos em parte do tempo da entrevista. Contudo, apenas dois entrevistados estavam com outros pacientes no quarto.

\section{Análise dos dados}

Os dados foram analisados por meio da análise de conteúdo, formando categorias segundo critério de repetição e relevância. As entrevistas foram transcritas na íntegra e, posteriormente, foram lidas e relidas, a fim de encontrar conteúdos importantes e recorrentes. A análise de conteúdo, segundo Turato (2003), consiste na transformação do conteúdo do documento com a finalidade de oferecer um significado, levando em consideração palavras pré-escolhidas pelo locutor, frequência de recorrência de certos termos, aparato e andamento do discurso. A intenção é que se possa ultrapassar o estágio descritivo, podendo fazer inferências e discussões a partir dos dados trabalhados. Complementando, Bauer e Gaskell (2008) afirmam que é preciso ir além do que é falado, procurando temas e funções com conteúdo comum. O objetivo principal da análise é procurar sentidos e compreensão por meio da imersão do pesquisador no corpus do texto.

A partir da análise, constituíram-se metodologicamente as categorias e subcategorias, procedimentos que consistem em colocar assuntos em relevo que merecem discussão em grandes tópicos (categorias). Uma vez que a categoria se mostra bastante diversificada quanto a seus elementos, as subcategorias passam a ter serventia (Turato, 2003).

No processo de categorização, é possível levar em conta o critério de repetição que preconiza que se atribuam destaque às colocações reincidentes, fazendo a investigação do que cada uma delas tem em comum. Além disso, pode-se categorizar, por meio do critério de relevância, em que não necessariamente um ponto é repetido, mas é considerado, segundo a ótica do pesquisador, uma fala rica em conteúdo e que se constitui um ponto central na construção dos significados dos entrevistados (Turato, 2003).

Após uma primeira leitura baseada numa atenção flutuante (Turato, 2003), em que pontos de significação adquiriram destaques, a análise da presente pesquisa continuou por meio da leitura e releitura tanto do pesquisador principal quanto de um segundo pesquisador, consolidando categorias que apresentavam repetição ou se constituíam em elementos centrais na compreensão das narrativas dos entrevistados.

\section{Aspectos éticos}

No presente estudo, foram mantidos os princípios éticos presentes na Resolução no 466/2012 do Conselho Nacional de Saúde (Brasil, 2012), que guia a ética em pesquisas com seres humanos. Dessa forma, foram respeitados os princípios da autonomia, beneficência, não maleficência, justiça e equidade, assegurando os direitos e deveres dos participantes da pesquisa à comunidade científica e ao Estado (Brasil, 2012). A pesquisa somente foi colocada em prática após a aprovação do Comitê de Ética da UFSM, sob o número CAAE: 31503914.1.0000.5346.

Foi ressaltado aos participantes, no Termo de Consentimento Livre e Esclarecido, que não haveria benefícios diretos a eles, porém, estariam ocupando uma posição de pessoas que estarão proporcionando, por meio de suas vivências, uma reformulação de conceitos e propagação de conhecimento. Além disso, tratando-se da vivência pessoal, havia o risco de que os participantes se sensibilizassem, estando disponível, dessa maneira, um atendimento psicológico caso fosse necessário.

O sigilo dos participantes será mantido e as informações somente poderão ser divulgadas de forma anônima, sendo elas mantidas na Avenida Roraima, prédio 74B, sala 3212A, Santa Maria-RS, CEP: 97105-340, por um período de cinco anos, sob os cuidados do pesquisador responsável. Após esse período, os dados serão destruídos.

\section{Resultados e discussões}

A vivência do câncer provoca uma ruptura na vida da pessoa, que passa a conviver com uma realidade desconhecida (Almeida, Rezende, Schall, \& Modena, 2010). Além disso, há o confronto com a ameaça de morte, o que faz com que os indivíduos se deparem com suas angústias, fragilidades e falta de sentido.

Desde os primeiros sinais da doença, o paciente costuma passar por diversos médicos e exames até chegar a um diagnóstico, processo este que, muitas vezes, é longo. Com o início do tratamento, o paciente passa a experienciar os procedimentos invasivos, que geram sofrimento e tornam o processo complexo e 
longo, permeado por sentimentos de dúvidas e incertezas. Dessa forma, o adoecimento e tratamento são perpassados por inúmeras limitações, acarretando angústias e sentimento de impotência (Ferreira, Dupas, Costa, \& Sanchez, 2010). Com isso, entende-se que o conjunto de mudanças que o câncer e o tratamento impõem e as angústias e os medos que surgem frente a esse processo exigem do indivíduo a construção de sentidos para o adoecimento e também para o viver nessas condições.

Nesse contexto, buscou-se investigar quais recursos são utilizados pelos pacientes para construir sentidos para o processo de adoecimento e tratamento. Na presente pesquisa, a religiosidade, em suas diversas formas, ganhou destaque. Deus foi colocado enquanto principal depositário da esperança de cura, situado como protetor e como responsável pelo momento que os pacientes estavam vivenciando. Dentre os resultados alcançados mediante a análise dos dados, seguindo o critério de repetição e relevância das informações apresentadas pelos participantes da pesquisa, as categorias se destacaram por pontuar questões relativas à sustentação divina, às explicações de ordem religiosa e relativas, também, à fé como defesa que falha e como evidencia de uma contradição.

\section{A sustentação divina}

Nesta categoria destacou-se a ideia de que a doença e a proximidade com a morte convocaram os participantes a falar de um ser superior, que está no controle e pode oferecer alguma compreensão para a situação que está sendo vivenciada. Nas falas analisadas, o desejo de cura deixa de estar depositado exclusivamente nos médicos e nos meios técnicos científicos para estar direcionado a uma cura mágica, que se relaciona à religião. Sugere-se que o paciente busca o sagrado a fim de controlar algo que não pode ser controlado, uma vez que a proximidade da finitude se torna cada vez mais evidente.

De maneira geral, o indivíduo não tende a encarar abertamente seu fim, lançando um olhar sobre a possibilidade de sua morte apenas de modo ocasional e com certo temor. Pensa-se que uma dessas ocasiões é quando sua vida está ameaçada por uma doença. O fato de o paciente receber a notícia que tem câncer já pode o remeter a sua possível morte. Isso se deve ao fato de que, frequentemente, as pessoas associam um tumor maligno à doença fatal, como indicamos anteriormente (Kübler-Ross, 1981). O ser humano, ao se deparar com uma situação assustadora e a proximidade da morte, recorre, muitas vezes, à crença na existência de um ser superior, apegando-se a um suposto poder da fé, sendo este o recurso utilizado para dar conta de uma situação que parece irreversível para os métodos científicos, uma vez que "para Deus nada é impossível” (Rzeznik, \& Dall'Agnol, 2000).

Além disso, a superação de um momento difícil pode levar ainda a intensificação da sua fé, fazendo com que o indivíduo possa se sentir mais próximo de Deus, valorizando seu lado espiritual (Rzenik, \& Dall'Agnol, 2000). Em um sentido geral, o apego a Deus não se mostra como uma prática nova para tais pessoas, mas como uma crença que passa a ser fortalecida, especialmente quando os problemas se tornam demasiadamente desestruturantes, esvaziados de sentido (Ferreira et al., 2010), como reflete a fala a seguir: "Ah, sim... A gente se apega, né... e é o que dá força pra gente continuar vivendo... não só os médicos, também tem que... tem que ter uma fé também, né " (E1, 42, M).

$\mathrm{Na}$ fala de E1, fica claro que depositar sua cura apenas nos médicos não parece suficiente, uma vez que os recursos científicos muitas vezes não dão suporte para a construção de sentidos para o momento em que está vivendo. Para dar conta do que se evidencia através da doença, a grande maioria dos pacientes faz uso de algo que transcende o mundo cotidiano, apegando-se a explicações mágico-religiosas. Dessa maneira, algumas falas deixam clara a posição que Deus ocupa enquanto curador de sua doença. Como exemplo disso, na fala que segue, E2 deixa de atribuir qualquer responsabilidade sobre sua sobrevivência aos médicos, para delegar a Deus:

Muito, muito, nossa, Deus tem me ajudado muito, Deus tem me confortado, tem me dado graça pra continuar, pra ficar firme, forte, sabe, acho que se não fosse Deus eu nem estaria aqui, eu acho, porque na segunda vez que eu internei deu duas paradas cardíacas, então eu acredito que foi Deus (E2, M, 22).

Diante disso, evidencia-se a posição que Deus, sendo detentor de um poder que ultrapassa os métodos científicos, ocupa. Situa-se como principal depositário das expectativas de cura, assim como responsável por dar suporte de significações que permitem que o paciente continue vivendo e siga o tratamento. Com isso, a cura da doença é esperada de Deus e não dos métodos técnico-científicos. 


\section{As explicações de ordem religiosa}

Além de Deus ser o depositário das expectativas de cura, fica evidente o quanto ele representa uma explicação, trazendo certo sentido à vivência pela qual os pacientes estão passando, uma vez que a doença traz uma ruptura e um esvaziamento dos sentidos construídos até então, confrontando-os com sua fragilidade. O desamparo que esse conjunto de fatores traz convoca o paciente a buscar explicações para tal. Frequentemente, como ilustra a presente categoria, encontram-nas na religião, em Deus.

Em relação às explicações científicas, cita-se um estudo sobre câncer e sua representação simbólica, no qual se verifica que os pacientes com câncer não demonstram um interesse maior em relação a explicações teóricas sobre a doença. Inicialmente, na maioria das vezes, há uma investigação acirrada em todas as vias sobre tal. Contudo, com a evolução da doença, a mudança de prognóstico e a finitude que se aproxima, o interesse do doente muda, ocasionando uma diminuição da necessidade de tantas informações. Os pacientes desistem de querer entender tantos detalhes sobre a doença e passam a pedir a Deus por luz e uma nova chance. Sendo assim, buscam explicações para além do biológico e do científico, como nas explicações sobrenaturais (Dóro et al., 2004), como se pode visualizar no recorte:

Só me confirmou coisas que eu já acreditava, em Deus, em Jesus, em ficar bom... Deus tá cuidando de mim... eu creio nisso, eu creio que eu vou ficar bom, eu sei que isso é uma prova que eu tô passando e que Deus que sabe de todas as coisas [...] porque se fosse pra mim ter morrido, eu tinha morrido aquele dia no Arroio, porque eu tava todo roxo, tava todo com as mãos inchadas, tava todo inchado, depois te vindo de novo e ter duas paradas cardíacas, então eu acredito que isso não é pra morte e sim pra glória de Deus (E2, M, 22).

Percebe-se, com a fala de E2, o quanto as explicações científicas são deixadas de lado em prol da construção de sentidos através da religião. Na fala, ao colocar Deus como detentor de todo saber, evidencia a construção de uma explicação que tenta fazer frente à situação de impotência e desamparo que se encontra. Além disso, sua crença em Deus o faz acreditar que a sua vivência da doença não é em vão, mas para "glória de Deus", trazendo mais um sentido para a doença. Com isso, a vivência da doença ganha um propósito e deixa de ser algo inexplicável, passando a ser uma designação de alguém superior que lhe quer bem.

Os fatores que mais predominaram no discurso dos participantes sobre a religiosidade foram, primeiramente, a busca de significado e suporte emocional. Assim, evidencia-se que a religiosidade oferece forte assistência tanto no amparo quanto na busca de significados, variáveis estas apontadas como importantes no enfrentamento da doença (Fornazari, \& Ferreira, 2010). Nessa direção, Quintana (1999) assinala que a doença traz um conjunto de sintomas que não fazem sentido ao paciente, pois remetem a algo que carece de uma significação coerente. Portanto, é preciso que se construa uma linguagem socialmente aceita, organizando os sintomas em um sistema de significação e trazendo uma reordenação e ressignificação. Esse processo de atribuição de sentido contribui para a aceitação da doença, uma vez que a dor, articulada a algo que faça sentido, deixa de ser arbitrária e intolerável, segundo o autor. No estudo de Fornazari e Ferreira (2010) sobre a religiosidade/espiritualidade em pacientes oncológicos, foi apontado que grande parte dos participantes delegou à religiosidade a causa de sua cura, transformação de vida ou contribuições do tratamento, o que sugere que eles atribuem a um "ser supremo" sua possibilidade de melhora/cura (Fornazari, \& Ferreira, 2010).

A religião, portanto, está intimamente ligada à possibilidade de sair de uma posição de total impotência para uma posição em que algum controle é possível ou percebido. Os participantes transparecem nas suas falas a entrega da responsabilidade do destino de suas vidas a esse "ser supremo". Dessa forma, a religiosidade alimenta a ideia de que existe alguém maior que está controlando o percurso de suas vidas e que, além disso, esse ser deseja o melhor para eles. Esse fator, sem dúvidas, contribui para redução do estresse e ansiedade, uma vez que aquilo que não se tem controle é fonte de ansiedade e preocupação (Fornazari, \& Ferreira, 2010).

Dessa maneira, pode-se pensar, além disso, o quanto a religião dá um sentido para a posição passiva em que se encontram os pacientes. De alguma forma, poder "entregar" suas vidas a Deus, ao contrário do que inicialmente poderíamos pensar, confere a eles certa posição ativa nesse processo, podendo controlar, mesmo que de forma ilusória e deslocada, o que está lhes acontecendo. Isso por que por meio da fé se pode ter acesso a esse Deus e, por sua vez, ter certo controle da doença, deixando de estar totalmente a mercê dela. 
Na sequência, na fala de E10, fica claro o quanto há crença no controle de Deus, que é ele quem vai tomar uma providência em relação à sua condição: "Ah...eu acredito em Deus porque ele ainda vai... me dá uma providência, né. Mas sem ele nós não somos ninguém. Não é?" (E10, M, 73). Na mesma direção, o recorte de E4 ilustra o quanto seu apego a Deus traz uma direção, uma vez que sem ele "não sabe para onde vai":

Mas... graças a Deus, tô operado, tô bem [...] Acredito em Deus! Sou católico, mas crente de Deus. É Deus que me defende, né, se eu to aqui é graças a ele. Tô bem, eu não tenho outra coisa no mundo maior do que Deus [...] Uma vida assim, se não tem Deus o que que vai ser, vai pra onde, né? (E4, M, 67).

Além disso, a fala de E2 denota uma busca de sentido para a doença, que acredita que seja para tocar a sua família sobre a existência de Deus.

Não... frustração não, mas... eu não posso perguntar por que pra Deus, mas sim para que, ele sabe de todas as coisas... talvez foi pra mexer com a minha família, pra balança eles, que existe um Deus e que ele pode tudo, todas as coisas porque meu pai era um cara muito duro e Deus teve que tocar na coisa que ele mais amava pra ele vê que não é do jeito que ele pensa (E2, $M, 22)$.

Com isso, entende-se que, diante da falta de sentido, a religião, ou seja, as explicações mágico-religiosas, preenche, pelo menos em parte, o vazio de sentido aberto pela doença. Diante disso, ela permite a construção de uma série de sentidos que, frequentemente, o indivíduo não encontra na ciência ou em outros campos de sua vida.

\section{A fé: uma defesa que falha?}

A religião, frequentemente, oferece apoio, suporte, é fonte de explicações e depositária de expectativas de cura. Apesar disso, as pessoas, muitas vezes, deixam aparecer certa insegurança e temor. Os pacientes e familiares, comumente, fazem uso da fé para suportar os desafios da doença, assim como para se confortarem diante da impossibilidade de cura. Apesar de, muitas vezes, apegarem-se à fé para suportar suas ansiedades, angustiarem-se frente à possibilidade de alteração do resultado dos exames (Salci, \& Marcon, 2010).
Como indicado anteriormente, a religião exerce um papel muito importante enquanto suporte, apoio ou fonte de explicações. Contudo, ela parece não poder abranger inteiramente as angústias que emergem frente à morte, pois, apesar de sua fé, os acometidos pelo câncer temem o prosseguimento da doença e a proximidade da finitude. A fala seguinte ilustra $o$ estado de angústia e ansiedade que os entrevistados se encontram mesmo estando voltados para uma religião:

Ah... não sei... nunca tive esse negócio de fazer quimio... Sempre tive medo, né. Jamais pensei que ia acontecer comigo, mas... aconteceu. Mas não sei... não sei... qual é a [silêncio] não sei... ter fé em Deus, ele sabe o que faz. Se ele me deu essa cruz pra carregar eu tenho que carregar, né? (E6, M, 43).

A fala é ilustrativa do quanto, mesmo devotos a Deus, os indivíduos acabam se confrontando com certos medos e ansiedades que nem sua fé pode os proteger. Além disso, o diagnóstico, bem como o tratamento, representa uma longa jornada em uma nova etapa de suas vidas. A realização de exames, por exemplo, torna-se uma nova necessidade em suas rotinas, o que desperta sentimentos de incerteza, ansiedades, angústias e temores frente ao resultado dos mesmos que determinarão o rumo a ser seguido, tornando-se, assim, incerto seu futuro (Salci, \& Marcon, 2010). Tais angústias e incertezas se mostram presentes na fala que segue:

Porque eu acho assim, o que tem que ser, será. Deus sabe o que faz, né. Hoje, eu penso comigo, hoje a medicina está muito adiantada, então, se for pra mim morrer com câncer, mas que eu não tenha dor [se emociona], porque hoje tem remédio pra tirar dor do corpo da gente (E7, M, 75).

Com base nesse depoimento, pode-se entender o quanto, nesse caso, Deus não parece suficiente para salvá-lo da dor e da morte, uma vez que evidencia a importância e avanço da medicina. Portanto, entende-se que, apesar de a fé trazer conforto, suporte e possibilitar a construção de sentidos, ela não se constitui em uma crença cega que se transforma em negação de seu estado. Por um lado, sua crença em Deus tranquiliza, uma vez que traz um sentido, ainda que da ordem da crença, para a doença. Por outro lado, sua fé não o impede de reconhecer seu estado e a proximidade da morte, o que permite que o paciente, ao se defrontar 
com sua situação, possa ir construindo possibilidades de elaboração. Dessa maneira, a fé, por não dar conta de forma absoluta da impotência do paciente, possibilita a ele construir um sentido nesse momento de sua vida e, assim, evita o desespero. Porém, não impede o sofrimento, fator necessário para um processo de luto pela situação que está passando.

\section{A fé: evidência de uma contradição}

$\mathrm{Na}$ fala dos participantes, por um lado, a religião aparece como suporte de bem-estar e tranquilidade, mas, por outro, parece representar uma tentativa desesperada de encontrar uma possibilidade de cura. A contradição consiste no discurso de estarem bem com a sua situação e não se abalarem com ela, porém, ao mesmo tempo, relatam que "só Deus pode salvar", ou só com ele poderiam ser felizes.

Uma vez que nem todos os pacientes sabem diretamente pela equipe de saúde sobre seu estado, muitos deles acabam tendo conhecimento por meio do seu cotidiano de exames, procedimentos sem sucesso, entre outros. Ainda assim, parece existir, na maioria das falas dos entrevistados, certa negação quanto a gravidade da sua situação. Contudo, esse saber, que busca ser negado, acaba aparecendo em seus discursos acerca da religião, os quais evidenciam angústias, medos e desespero.

Em seu estudo com pacientes terminais, Kübler-Ross (1981) afirma ter havido um fato que se destaca: todos os pacientes, quer tendo sido informados ou não, sabiam da gravidade do seu estado. Por ser sempre doloroso tratar desse assunto, o paciente acaba aceitando qualquer mensagem, implícita ou explicita, para não falar sobre ele. Nos pacientes existe, vez ou outra, a necessidade de negação. Posteriormente, essa necessidade vai e volta, e a maioria dos pacientes não se serve da negação por muito tempo, podendo conversar sobre a realidade do seu estado e, ao mesmo tempo, demonstrar incapacidade de lidar realisticamente com o assunto (Kübler-Ross, 1981).

Till (2004) aponta, com base em seu estudo sobre as estratégias de enfrentamento utilizadas pelos adolescentes em sua vivência com câncer, que eles se utilizaram da estratégia de escape, termo em inglês que significa fugir, fingindo que a vivência da doença não estava acontecendo, buscando não pensar sobre isso, realizando diversas atividades de distração, entre outras estratégias para fuga da situação. Iamim e Zagonel (2011), ao escreverem sobre as estratégias de copingdos adolescentes frente ao câncer, utilizam o termo escape como sinônimo de negação. Assim, pensa-se sobre a aproximação do escape ao mecanismo de negação. Ainda, Almanza-Muñoz e Holland (2000) propõem que o mecanismo de negação é a primeira fase pela qual o paciente oncológico passa, na qual há uma anestesia emocional, seguida por momentos de confusão, agitação emocional e disforia.

Além disso, os enfermos costumam fazer acordos que adiem o inevitável desfecho, em que a maioria deles é feito com Deus (Kübler-Ross, 1981). A fala a seguir ilustra um pouco da contradição existente entre não se abalar com a doença, mas, ao mesmo tempo, depositar as expectativas de cura apenas em Deus e não em possibilidades médicas: "Esse é o... Esse aí é o que tem o poder, né, se não for ele, então, nós estamos tudo perdido. Tem que ter fé em Deus que tudo dá certo" (E3, M, 44).

Observa-se o quanto a religião possibilita a construção de significados que coexistem paradoxalmente. Por um lado, serve para camuflar seu verdadeiro saber a respeito de seu estado, quando vem representada por uma salvação que, possivelmente, pode não acontecer. Por outro lado, acaba denunciando tal saber, quando aparece no discurso que só Deus pode salvar, demonstrando, assim, que tamanha é a gravidade de sua situação e que as possibilidades terapêuticas não dão conta de sua cura ou salvação. No que se refere a "só Deus poder salvar", as seguintes falas remetem a uma tentativa de mostrar-se bem, contudo, ao que parece, só Deus pode fazer isso: "Eu não tenho medo, sabe, eu penso assim que a vida Deus deu e ele tira, né, quando chega a hora Deus leva, né, então a gente não tem que ter medo..." (E8, F, 29); ou ainda: "Que é só se agarrando com Deus pra ser feliz [chora] [silêncio]. Demais eu tô... conforme com Deus..." (E5, M, 67).

Compreende-se que a doença situa o indivíduo diante de sua fragilidade e desamparo, estando desarticulada de significados. Diante disso, é preciso considerar a importante função que a religião ocupa frente a esse vazio, pois oferece ao paciente com câncer a possibilidade de construir significados para a doença e para sua vida nessa situação. Dessa maneira, ele se lança na direção dessa busca de sentido, na tentativa de sair de uma situação de desamparo, de impotência. A crença nas curas mágicas traz suporte e conforto frente à procura de alternativas às técnicas-científicas, porém, a religiosidade não pode dar conta sozinha desse vazio de sentidos, o que evidencia a importância de outras possibilidades de apoio aos pacientes. 


\section{Considerações finais}

$\mathrm{O}$ adoecimento, de modo geral, convoca o confronto com a finitude. O câncer, em especial, carrega um estigma social que o associa diretamente à morte e ao sofrimento. Esses fatores colocam o indivíduo frente a sua fragilidade e desamparo, diante de um vazio de sentidos.

Frente à ausência de significados e explicações para tal vivência, o paciente busca construí-los. A religião e a fé aparecem como principais fornecedoras de sentido, uma vez que, dificilmente, o encontram em outros âmbitos de suas vidas. Dessa forma, entende-se que, diante do vazio de significados, do desamparo e da fragilidade que a doença traz, o paciente acometido por câncer busca algo que lhe possa trazer certo sentido e controle sobre um evento que ocorreu e para o qual, frequentemente, não há. Portanto, esse indivíduo, muitas vezes, encontra tais explicações no âmbito mágico-religioso que, além disso, traz um controle ilusório da doença.

Deus aparece como principal depositário das expectativas de cura. Porém, muitas vezes, o apego fervoroso dos pacientes a Deus denuncia certa contradição. Ao passo que se esforçam, em seu discurso, para deixar claro que sua fé os traz tranquilidade diante da doença, apegam-se, desesperadamente, a uma cura que só pode vir de algo mágico e, não mais, dos meios técnico-científicos. Com isso, a fé é capaz de oferecer suporte e trazer certo sentido a vivência. Apesar disso, não pode dar conta sozinha de todas as angústias e temores frente à morte. Frequentemente, os entrevistados deixam transparecer, em seus discursos, anseios que ultrapassam o poder da religiosidade. Por isso, entende-se a importância da abertura de outras possibilidades para a construção de sentidos para que o paciente consiga lidar com a doença e a proximidade da morte. Destaca-se o valor da esfera subjetiva e singular de cada pessoa para a construção de sentidos para o adoecimento. Ainda, sugere-se a relevância de os pacientes serem escutados, podendo expressar suas angústias e processar melhor a vivência pela qual estão passando, construindo um sentido que lhes possibilite lidar com a doença e a finitude.

Frisa-se, também, a magnitude do estudo para fornecer subsídios para os profissionais da saúde, bem como para a comunidade científica, que trabalham com esses pacientes. Nesse sentido, ressalta-se a importância de os profissionais da saúde poderem oferecer maior apoio a esses pacientes, de forma a facilitar que se construam formas de significar a doença, auxiliando-os a lidar com a situação de desamparo em que se encontram.

Apesar do número de participantes ser limitado, seus discursos permitem um aprofundamento e percepção da complexidade de suas experiências. Dessa maneira, a pesquisa proporciona dados que permitem uma contribuição para o - ainda restrito - espaço de compreensão e produção acerca dos pacientes confrontados com a finitude.

\section{Referências}

Almanza-Muñoz J. J., \& Holland, J. C. (2000). Psicooncologia: estado actual y perspectivas futuras. Revista del Instituto Nacional de Cancerología, 46(3), 196-206. Recuperado de http://www.cuidadospaliativos.org/archives/Psicooncologia,\%20estado\%20actual\%20y\%20perspectivas\%20futuras.pdf

Almeida, S. S. L., Rezende, A. M., Schall, V. T., \& Modena, C. M. (2010). Os sentidos da corporeidade em ostomizados por câncer. Psicologia em Estudo, 15(4), 761-769. https://doi.org/10.1590/S1413-73722010000400012

American Cancer Society. (2014). What is advanced cancer? Recuperado de http://www.cancer.org/treatment/ understandingyourdiagnosis/advancedcancer/advanced-cancer-what-is

Bauer, M. W., \& Gaskell, G. (2008). Pesquisa qualitativa com texto, imagem e som: um manual prático (7a ed., P. Guareschi, trad.). São Paulo, SP: Vozes.

Brasil. (2012). Conselho Nacional de Saúde. Resolução $N^{\circ} 466$, de 12 de dezembro de 2012. Aprova diretrizes e normas regulamentadoras de pesquisas envolvendo seres humanos. Brasília, DF: o autor. Recuperado de http:// conselho.saude.gov.br/resolucoes/2012/Reso466.pdf

Caetano, E.A., Gradim, C. V. C., \& Santos, L. E. S. (2009). Câncer de mama: reações e enfrentamento ao receber o diagnóstico. Revista de Envermagem UERJ, 17(2), 257-61. Recuperado de http://www.facenf.uerj.br/ v17n2/v17n2a21.pdf 
Reis, C. G. C.; Farias, C. P.; Quintana, A. M. (2016). Suporte da Religiosidade para Pacientes com Câncer Avançado.

Campos, E. B. V. (2013). Considerações sobre a morte e o luto na psicanálise. Revista de Psicologia da UNESP, 12(1), 13-24. Recuperado de http://pepsic.bvsalud.org/pdf/revpsico/v12nl/a03.pdf

Combinato, D. S., \& Queiroz, M. S. (2006). Morte: uma visão psicossocial. Estudos de Psicologia (Natal), 11(2), 209-216. https://doi.org/10.1590/S1413-294X200600020001

Dóro, P. M., Pasquini, R., Medeiros, C. R., Bitencourt, M. A., \& Moura, G. L. (2004). O câncer e sua representação simbólica. Psicologia: Ciência e Profissão, 24(2), 120-134. https://doi.org/10.1590/S1414-98932004000200013

Doyle, D., Hanks, G. W. C., \& MacDonald, N. (2006). As origens da medicina paliativa. In M. T. A. Figueiredo (Orgs.), Coletânea de textos sobre cuidados paliativos e tanatologia (pp. 14-15). São Paulo, SP: Setor de Cuidados Paliativos da Disciplina de Clínica Médica da Unifesp. Recuperado de http://www.nutrabem.ind.br/ cuidadospaliativosetanatologia.pdf

Ferreira, N. M. L., Dupas, G., Costa, D. B., \& Sanchez, K. O. L. (2010). Câncer e família: compreendendo os significados simbólicos. Ciência Cuidado e Saúde, 9(2), 269-277. https://doi.org/10.4025/cienccuidsaude.v9i2.8749

Fornazari, S. A., \& Ferreira, R. E. R. (2010). Religiosidade/espiritualidade em pacientes oncológicos: qualidade de vida e saúde. Psicologia: Teoria e Pesquisa, 26(2), 265-272. https://doi.org/10.1590/S0102-37722010000200008

Geronasso, M. C. H., \& Coelho, D. (2012). A influência da religiosidade/espiritualidade na qualidade de vida das pessoas com câncer. Saúde \& Meio Ambiente, 1(1), 173-187.. Recuperado de http://www.periodicos.unc.br/ index.php/sma/article/view/227

Gil, A. C. (2002). Como elaborar projetos de pesquisa (4a. ed.). São Paulo, SP: Atlas.

Guerrero, G. P, Zago, M. M. F, Sawada, N. O., \& Pinto, M. H. (2011). Relação entre espiritualidade e câncer: perspectiva do paciente. Revista Brasileira de Enfermagem, 64(1), 53-9. https://doi.org/10.1590/S0034-71672011000100008

Iamin, S. R. S., \& Zagonel, I. P. S. (2011). Estratégias de enfrentamento (coping) do adolescente com câncer. Psicologia Argumento, 29(67), 427-435. Disponível em http://www2.pucpr.br/reol/pb/index.php/pa?ddl=5788\&dd99=view\&dd98=pb

Kübler-Ross, E. (1981). Sobre a morte e o morrer: o que os doentes terminais têm para ensinar a médicos, enfermeiras, religiosos e aos seus próprios parentes. São Paulo, SP: Martins Fontes.

Laplanche, J., \& Pontalis, J.-B. (2001). Vocabulário de psicanálise. São Paulo, SP: Martins Fontes.

Menezes, N. N. T, Schulz, V. L., \& Peres, R. S. (2012). Impacto psicológico do diagnóstico do câncer de mama: um estudo a partir dos relatos de pacientes em um grupo de apoio. Estudos de Psicologia, 17(2), 233-240. https:// doi.org/10.1590/S1413-294X2012000200006

Minayo, M. C. S. (2010). O desafio do conhecimento: pesquisa qualitativa em saúde (12a ed.). São Paulo, SP: Hucitec.

Mori, V. D. (2015). Os sentidos subjetivos configurados na experiência do câncer: um estudo de caso. In F. G. Rey, \& J. Bizerril (Orgs.), Saúde, cultura e subjetividade: uma referência interdisciplinar (pp. 115-130). Brasília, DF: UniCEUB

Quintana, A. M. (1999). A ciência da benzedura. São Paulo, SP: EDUSC.

Quintana, A. M., Kegler, P., Santos, M. S., \& Lima, L. D. (2006). Sentimentos e percepções da equipe de saúde frente ao paciente terminal. Paidéia, 16(35), 415-425. https://doi.org/10.1590/S0103-863X2006000300012

Redon, S. A. (2008). A interpretação da doença e a busca de sentido: um estudo com pacientes em tratamento de câncer. Revista Anthropológicas, 19(2), 75-80. Recuperado de http:/ /www.revista.ufpe.br/revistaanthropologicas/index.php/revista/article/view/97

Rzeznik, C., \& Dall'Agnol, C. M. (2000). (Re)Descobrindo a vida apesar do câncer. Revista Gaúcha de Enfermagem, 21(esp.), 84-100. Recuperado de http://hdl.handle.net/10183/23488

Salci, M. A., \& Marcon, S. S. (2010). A convivência com o fantasma do câncer. Revista Gaúcha de Enfermagem, 31(1), 18-25. https://doi.org/10.1590/S1983-14472010000100003

Sontag, S. (1984). A doença como metáfora (6a ed.). Rio de Janeiro, RJ: Graal.

Till, T. (2004). Coping with cancer: the adolescent experience. (Doctoral thesis). Australian Catholic University, Brisbane.

Trincaus, M. R., \& Corrêa, A. K. (2007). A dualidade vida-morte na vivência dos pacientes com metástase. Revista da Escola de Enfermagem da USP, 41(1), 44-51. https://doi.org/10.1590/S0080-62342007000100006 
Turato, E. R. (2003). Tratado da metodologia da pesquisa clínico-qualitativa: construção teórico-epistemológica, discussão comparada e aplicação nas áreas da saúde e humanas. Petrópolis, RJ: Vozes.

Cristine Gabrielle da Costa dos Reis

Mestre em Psicologia pela Universidade Federal de Santa Maria, Santa Maria - RS. Brasil.

E-mail: cristinecostareis@hotmail.com

\section{Camila Peixoto Farias}

Doutora pela Universidade Federal do Rio de Janeiro, Rio de Janeiro - RJ. Docente da Universidade Federal de Santa Maria, Santa Maria - RS. Brasil.

E-mail: pfcamila@hotmail.com

\section{Alberto Manuel Quintana}

Doutor pela Universidade Federal de Santa Maria, Santa Maria - RS. Docente da Universidade Federal de Santa Maria, Santa Maria - RS. Brasil.

E-mail: albertomquintana@gmail.com

Endereço para envio de correspondência:

Rua São Francisco, 287. Bairro Nossa Senhora do Rosário. CEP: 97010-450.

Santa Maria, RS, Brasil.

Recebido 08/01/2015

Reformulado 01/11/2016

Aprovado 13/12/2016

Received 01/08/2015

Reformulated $11 / 01 / 2016$

Approved 12/13/2016

Recibido 08/01/2015

Reformulado 01/11/2016

Aceptado 13/12/2016

Como citar: Reis, C. G. C., Farias, C. P., \& Quintana, A. M. (2017). O vazio de sentido: suporte da religiosidade para pacientes com câncer avançado. Psicologia: Ciência e Profissão, 37(1): 106-118. https://doi.org/10.1590/1982-3703000072015

How to cite: Reis, C. G. C., Farias, C. P., \& Quintana, A. M. (2017). Emptiness of sense: religiosity support for patients with advanced cancer. Psicologia: Ciência e Profissão, 37(1): 106-118.

https://doi.org/10.1590/1982-3703000072015

Cómo citar: Reis, C. G. C., Farias, C. P., \& Quintana, A. M. (2017). El vacío de sentido: soporte de la religiosidad para pacientes con cáncer avanzado. Psicologia: Ciência e Profissão, 37(1): 106-118. https://doi.org/10.1590/1982-3703000072015 